This item was submitted to Loughborough's Research Repository by the author.

Items in Figshare are protected by copyright, with all rights reserved, unless otherwise indicated.

\title{
An empirical examination of the growing phenomenon of off-site residential car parking provision: the situation at UK airports
}

PLEASE CITE THE PUBLISHED VERSION

http://dx.doi.org/10.1016/j.tra.2013.07.006

PUBLISHER

(C) Elsevier

VERSION

AM (Accepted Manuscript)

LICENCE

CC BY-NC-ND 4.0

\section{REPOSITORY RECORD}

Budd, Lucy C.S., Stephen G. Ison, and Thomas Budd. 2013. "An Empirical Examination of the Growing Phenomenon of Off-site Residential Car Parking Provision: The Situation at UK Airports". figshare. https://hdl.handle.net/2134/13165. 
This item was submitted to Loughborough's Institutional Repository (https://dspace.lboro.ac.uk/) by the author and is made available under the following Creative Commons Licence conditions.

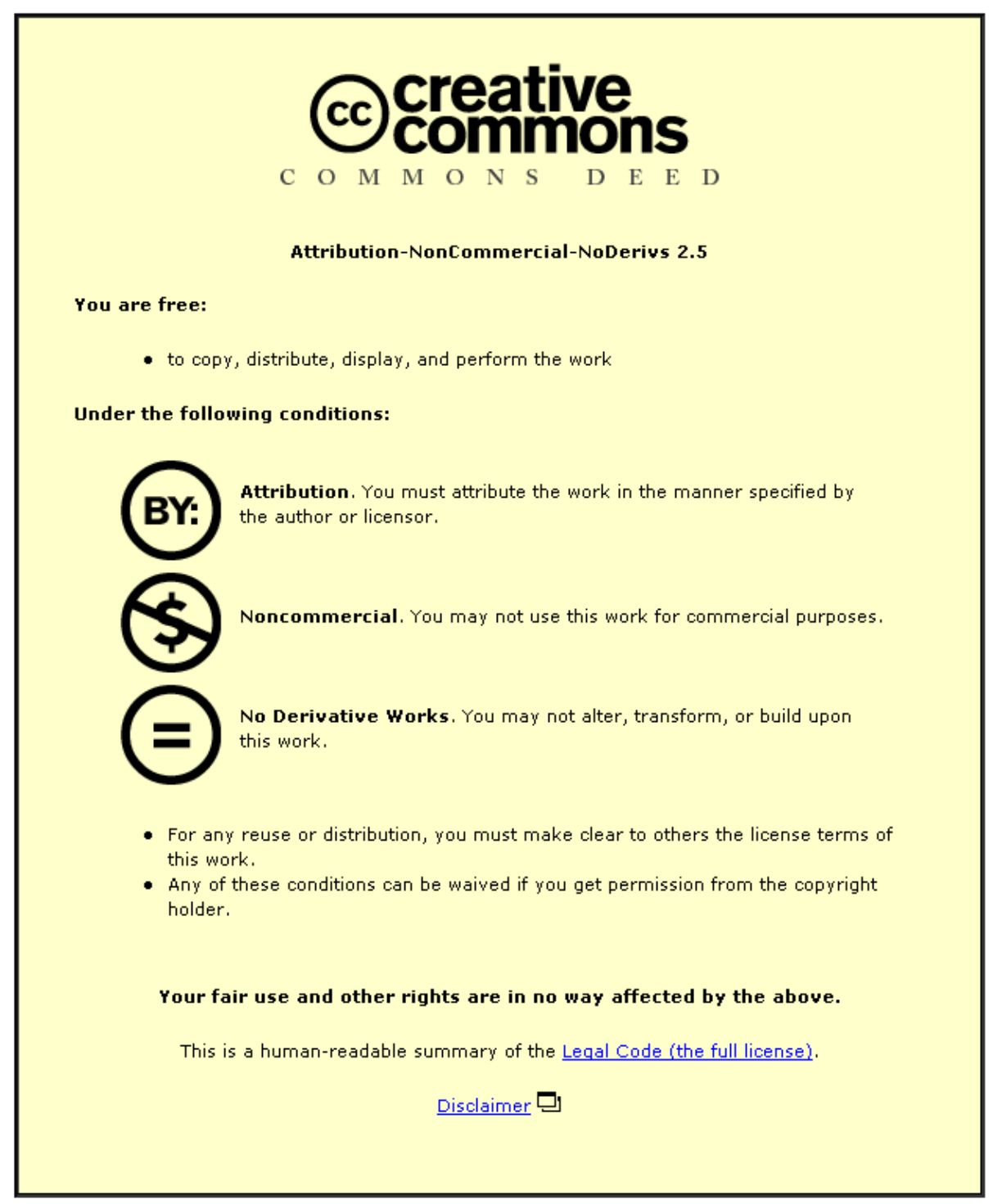

For the full text of this licence, please go to: http://creativecommons.org/licenses/by-nc-nd/2.5/ 
An empirical examination of the growing phenomenon of off-site residential car parking provision: the situation at UK airports.

Dr Lucy Budd (corresponding author)

Lecturer in Transport Studies

Transport Studies Group

School of Civil and Building Engineering

Loughborough University

Leicestershire LE11 3TU

United Kingdom

E-Mail: L.C.S.Budd@Iboro.ac.uk

Tel: +44 (0)1509 223409

Professor Stephen Ison

Professor of Transport Policy

Transport Studies Group

School of Civil and Building Engineering

Loughborough University

Leicestershire LE11 3TU

United Kingdom

E-Mail: S.G.Ison@lboro.ac.uk

Tel: +44(0)1509 222605

Mr Thomas Budd

PhD Student

Transport Studies Group

School of Civil and Building Engineering 


\author{
Loughborough University \\ Leicestershire LE11 3TU \\ United Kingdom \\ E-mail: T.Budd@lboro.ac.uk
}

\title{
Abstract
}

Parking management is a strategy that has been extensively employed by authorities and organisations world-wide in an attempt to address traffic-related congestion and associated environmental impacts. Airports are no exception and parking control and pricing regimes are used to raise additional revenue and manage traffic demand.

However, within the last five years a new trend in unregulated off-site, predominately residential, car parking provision around UK airports has emerged and rapidly grown in popularity. The aim of this paper is to investigate this new phenomenon. Through an in-depth analysis of three self-styled „parking marketplace" websites, this paper provides an empirical examination of the growing phenomenon of off-site residential car parking provision around the UK"s 25 busiest passenger airports. Data is provided on the supply and demand for these alternative spaces, insights into the physical location, attributes, and pricing regimes of these spaces is provided, and the potential implications for airport revenue, parking control, passenger safety/security, and airport-community relations are discussed. The empirical findings indicate that, while it is still at a relatively early stage, this parking phenomenon is experiencing rapid growth. The paper concludes by contending that airport operators and local authorities need to be cognisant of the existence of, and the challenges and opportunities associated with, alternative parking provision in order to be able to better plan for, and respond to, its complex revenue, planning, environmental, and consumer implications. 


\section{Keywords}

Car parking; airports; revenue; control; planning.

\section{Research highlights}

- There is a new trend in unregulated off-site, predominately residential car parking.

- This parking phenomenon is experiencing rapid growth.

- It has implications for airport revenue, parking control, passenger safety and security.

- Airport-community relations may also be affected.

- Airport operators need to be cognisant of its existence, challenges and opportunities.

- Airport operators need to respond to its revenue, planning, environmental and consumer implications.

\section{Introduction}

Parking is an important demand management instrument and one that is extensively used by public authorities and commercial organisations to address issues of traffic related congestion and environmental degradation. However, until recently, parking has been an area that has received relatively scant academic attention compared with other areas of transport demand management, such as road pricing. While research on parking and, more specifically, airport parking has begun to emerge in recent years (Aldridge et al, 2006; Ison et al, 2007; Ison et al, 2009; Straker et al, 2009), almost without exception this work focuses on the official and regulated on-airport and off-site commercial car parks and/or on the informal transient and unregulated car parks that operate from fields and industrial estates in the hinterland of major airports. Since airport parking and, in particular, unofficial alternative airport parking is an under researched area of academic inquiry, this paper provides an empirical examination of the growing phenomenon of alternative off-site car parking provision that is increasingly being made available on residential driveways and private properties around UK airports. The paper starts by situating the research within existing literature on airport parking and airport ground access, before the data collection method is described, the empirical findings presented, and their 
implications for airport revenue, parking control, passenger safety/security, and airport-community relations discussed.

\section{Parking provision and airport ground access}

In terms of airport ground access there are essentially three groups of people passengers, employees and 'meeters and greeters' - who need to access airports (Ashford et al, 1997; de Neufville and Odoni, 2003). While UK airports, in common with many around the world, are supporting the provision of public transportation to/from the passenger terminal, the private car remains one of the most important modes by which passengers, employees, and meeter-greeters access airports.

Private cars are typically considered to be the most convenient and flexible mode of transport for time critical journeys (Humphreys and Ison, 2005). At Manchester Airport in the UK, for example, $57 \%$ of passengers arrive by private car (DfT, 2011). Given the volume of airport access trips made by private cars and the differing demands and trip characteristics of these different user groups, it is unsurprising that airport parking has become an increasingly complex issue. The need to balance the needs of customers and employees as well as balancing the trade-off between generating car parking revenue and achieving environmental goals creates a challenging dilemma for airport authorities. The importance of car parking revenue to airports was recently demonstrated by Jacobs Consultancy (2010) who determined that, for US airports, as much as $26 \%$ of total airport revenues can be accounted for by parking revenue alone. Clearly, car parking provision and pricing regimes are strategically important to an airport's competitiveness and profitability (Ison et al, 2008).

As Ison et al (2007) have shown, there is a significant difference between the needs of airport passengers and airport employees with respect to parking. Passengers pay directly for their parking, whereas airport employees in the UK typically enjoy free 
parking. Staff permits are usually sold to the third-party organisations that operate franchises or businesses on the airport site who then allocate them to their employees but generally do not pass on the cost. One of the main motivations underpinning this policy relates to staff recruitment and retention (Ibid, 2007); airport authorities conventionally accommodate the demand for employee parking rather than seek to bring about modal shift (Ricondo et al, 2010).

'Meeters and greeters' and passengers being dropped off at an airport present less of an issue in terms of parking provision. However, as the price of parking increases, it is possible that more passengers will choose to be dropped off and picked up at the airport by friends or relatives (the so-called „kiss-and-fly" phenomenon) rather than pay to leave their vehicle on site. This would result in four vehicle trips being undertaken to and from the airport rather than two. In addition to the impact on parking revenue, increased „kiss-and-fly" traffic results in increased congestion. In response, airports such as East Midlands and Birmingham, in the UK, try to encourage long stay car parking and discourage „kiss-and-fly" journeys by charging private vehicles to enter designated „drop off" zones in front of the terminal building (East Midlands Airport, 2006; Birmingham International Airport, 2006).

At East Midlands Airport, for example, passenger car parking is demand responsive and not based on predict and provide (East Midlands Airport, 2006). Similarly, London Stansted airport (2008) has stated that it will only develop additional parking facilities as and when demand requires it. This would also appear to be important in a US context in that a study of fifteen US airports by Ricondo et al (2010) revealed that in a constrained airport parking environment passengers tended to prefer being dropped off and picked up by relatives rather than travel to the airport by public transport. 
While most of the academic and practitioner interest in airport parking has been concerned with on-site parking, increased attention is also turning towards the provision and management of off-site facilities. For example, at Scotland"s Edinburgh airport, a number of independent commercial companies provide courtesy coach services to and from the airport to connect the terminal complex to approximately 4,500 off-site spaces (Ison et al, 2009). At Glasgow Airport, as many as 13,000 offairport long stay spaces are provided by third party operators (BAA Glasgow, 2006). It is not unreasonable to assume that an increase in the price of airport parking could stimulate demand for alternative (and cheaper) off-airport parking.

The growth of off-airport parking has been countered, to a certain extent, by airports developing their own off-site park and ride provision. Manchester Airport in the northwest of England provides an example of this. According to the airport operator, meeting long-stay parking demand on the current site will be problematic as there competing priorities for land for operational uses. Furthermore, future development of long-stay is likely to be both on-site and off-site. The airport believes that this will provide a platform for a more extensive network of park and ride sites and remoter satellites linked to the passenger terminals by improved transport links, yet they also acknowledge that there are already a large number of off-site, independently operated, car parks (Manchester Airport, 2006). While this off-site parking relates to relatively formalised parking provision, another manifestation of off-site parking provision has recently emerged in the UK. Within the last 5 years, three "virtual parking marketplaces", dedicated websites that offer a fully searchable database of people who want to make additional money by renting out parking spaces on their residential driveways and in private car parks, have become operational. These websites act as „matchmakers" to link independent providers, who want to rent out a space on their property, with car drivers who are looking for cost effective and 
convenient places to park. Examples of these "virtual parking marketplaces" have been operating in the UK since 2006 and have rapidly grown in popularity. The provision of these alternative parking spaces, which typically undercut the parking charges levied by official operators, around airports has potentially serious revenue, planning and environmental implications for airport operators and local authorities. Through an in-depth analysis of three UK-based parking marketplace websites, this paper aims to investigate the scale and characteristics of this new development and discuss the implications of the growth of these alternative, predominately residential, off-site parking spaces for airport operators, local authorities, and consumers.

\section{Method}

To obtain data on the scale and scope of this alternative parking provision around UK airports, the online databases of the three active UK-based virtual parking marketplaces, parkatmyhouse.com, uk_park.com, and yourparkingspace.co.uk, were interrogated. For each website, 25 individual searches were run in order to identify all of the spaces that were advertised as serving each of the UK"s 25 busiest passenger airports (which collectively handled 209 million passengers or $98.9 \%$ of the UK"s total air passenger traffic in 2010 (CAA, 2010)). These airports ranged in size from London/Heathrow, which handled 65.5 million passengers in 2010, to Norwich International Airport in East Anglia with 426,000 passengers (Ibid, 2010). For each of the three websites, the full geographic name/descriptor of the airport (as opposed to any brand name) was entered as the search term. Thus, „Liverpool Airport" and „Belfast City Airport" (rather than „Liverpool John Lennon Airport" and "George Best Belfast City Airport") were used. Searches for spaces at the five airports located in and around the UK"s capital city - Heathrow, Gatwick, Stansted, Luton, and City - were all prefixed by the word „London". All 75 searches ( 25 for each of the three websites) were performed during the last two weeks of April and the first week 
of May 2011.

\section{Results}

1,244 providers of unofficial off-site car parking spaces were identified around the 25 airports we examined. Of the three websites, parkatmyhouse.com contained the highest number of providers, with 976 individuals advertising spaces at all but two of the 25 airports examined. Yourparkingspace.co.uk offered 238 providers at 20 different locations, while uk_park.com returned details of 30 providers at 13 different airports. The only airport that was not served by any of the three websites was Scotland's Inverness airport (see Table 1 with airports ranked by passenger numbers).

\section{Table 1 Number of residential parking providers by airport and website}

While it was possible to gain an appreciation of the scale and scope of each Website's operation and the number of providers and spaces that were available at each airport, the limited textual descriptions of the space(s) advertised through yourparkingspace.co.uk and uk_park.com, rendered detailed analysis of the location and attributes of the spaces they advertised impossible. In contrast, the postings on parkatmyhouse.com provided details about the number of spaces that each provider offered, where those spaces were located (i.e. private driveways, allocated parking bays, or residential garages), the cost of renting said space(s) on a daily, weekly, and/or monthly basis, a description of the security/access arrangements associated with using the space(s), data on when the provider had joined the website, and the number of bookings the provider had received. In addition, some providers had a feedback page on which past customers were invited to comment on the space(s) and the service that they had (or had not) received. In light of the ready availability of 
this data, information on the location, number, and attributes of all the off-site airport parking spaces advertised through parkatmyhouse.com forms the basis of the subsequent analysis.

\subsubsection{Parkatmyhouse.com}

Parkatmyhouse.com was launched on 22 September 2006 and markets itself as being the 'world's largest online parking marketplace' which was 'created to connect home and business owners who would like to earn money from renting their [car parking] space with drivers in need of a convenient, safe, and cost effective place to park' (parkatmyhouse.com homepage, 2011). The site acts as an online agent, matching independent individual suppliers of car parking spaces with potential users. In order to advertise a space, potential providers have to create a personal account and detail the approximate geographic location of the space(s) for rent (a full address and postcode is only supplied on booking completion), the number of spaces that are available, where those spaces are located (e.g. if they are on a private driveway, in a residential garage, or in an allocated parking bay), as well as the price of renting the space for different periods of time and any additional features, such as security lighting or CCTV, that are provided. The site enables providers to upload photographs of the space(s) that they have available for rent, should they wish to do so, and enable individual providers to append user reviews and customer feedback at the bottom of their profile to reassure potential customers about the veracity of the advertisement and the quality of the service that could be expected.

Each of the providers using parkatmyhouse.com has a unique username and identification number. Cross-checking these numbers against our growing dataset enabled us to identify multiple advertisements for the same space and eliminate double counting. This process meant that while the initial search of the website returned 106 hits for London Heathrow airport, for example, were able to ascertain 
that there were only 94 unique providers. The reason for this apparent discrepancy was that several providers had created new advertisements for their spaces but their original postings had not been deleted from the website. Once this data cleaning process had been completed, additional information concerning the month and year each provider had joined the website (if displayed), how many bookings they had received, as well as detailed information about the car parking space(s) being advertised was entered into a spreadsheet.

This resulting dataset included information about the provider, the number and physical location of the space(s) (i.e. whether they were located on a private driveway or in a private parking bay, private car park, private garage, or commercial car park), the price (in pounds Sterling) of renting the space(s) on a daily, weekly, monthly, or annual basis, and finally any security features or other facilities that were available. This latter category included information on whether the space(s) could be gated/secured, whether or not they were covered by security lighting or CCTV, if they permitted unrestricted $24 / 7$ access, whether the owners/providers of the space(s) offered transfers to/from the airport, details of any minimum stay requirements, and information about any other „value added" services, such as car valeting or pet sitting, that were available. In total, 17 separate pieces of information about each of the 976 individual providers was recorded. In each case, the provider's own written description of the space(s) available was used as the basis for the subsequent coding. If information about a particular attribute was not mentioned on the website, the corresponding data cell was left blank.

As of May 2011, 976 providers using parkatmyhouse.com could supply 2,839 alternative car parking spaces at all but two of the UK"s 25 busiest passenger airports (there were no spaces available at Belfast City or Inverness). Between the launch of 
the website, in September 2006, and the first week of May 2011, these spaces had collectively attracted 10,004 separate bookings. While this figure does not give an insight into the actual number of individual customers who booked spaces through the site (it is possible that a small number of loyal customers make repeat bookings), it does give an indication of the level of consumer demand for these alternative spaces.

Unsurprisingly, the UK"s four busiest passenger airports, London/Heathrow, London/Gatwick, London/Stansted, and Manchester, dominated the rankings for the airports with the highest number of individual locations, spaces, and bookings, however Southampton and Bournemouth airports on England"s south coast (the UK"s 18th and 22nd busiest passenger airports respectively) also returned high numbers of locations and bookings (Figure 1).

Figure 1 The number of providers, spaces, and bookings recorded at each of the UK's 25 busiest airports on parkatmyhouse.com.

Airports located in and around London dominated the rankings for providers, spaces, and bookings (Table 2).

Table 2 The top five airports by number of providers, spaces, and bookings on parkatmyhouse.com. Actual figures in brackets.

Detailed inspection of the resulting empirical dataset revealed five key attributes that are worthy of further examination, namely the physical location of the spaces, the average number of spaces offered per location and the average number of bookings each provider had attracted, the price of renting the spaces, the nature of additional 
facilities that were offered, and the growth in the number of independent providers between 2006 and 2011.

\subsection{Physical location of the spaces}

Of the 2,839 individual spaces identified, by far the majority $(79.7 \%)$ were on private residential driveways, with smaller numbers located in private car parks, private parking bays (i.e. spaces which are designated for use by a particular residential property but which are not located on an adjacent private driveway), private residential garages, and commercial car parks (Figure 2). The dominance of private driveways combined with a diversity of locations represents a potentially challenging situation for local authorities and airport operators as these alternative parking providers may not be known to the authorities and thus may be outside the remit and jurisdiction of local planning controls.

Figure 2 The physical location of the 2,839 spaces advertised through parkatmyhouse.com.

\subsection{Number of spaces and bookings}

Across the 23 airports, the average number of spaces offered by each provider was three (minimum one, maximum 100) and the average number of bookings each provider had received was 11 (although this latter figure hides considerable variation). 22 providers ( $2 \%$ of the total) had each received over 100 bookings (with the most popular provider attracting 753 bookings), while 589 (60\% of the total) had not received a single one. There appeared to be no obvious relationship between the price, the physical location of the space, the length of time the provider had been a member of the website, and the number of bookings received. However, the presence of a small number of providers (48) who had each received over 50 
bookings suggests that they might be attracting repeat custom from a loyal consumer base. Many of the profiles of the most popular providers (i.e. those who had attracted the highest number of bookings) appeared at the top of the page of search results in the form of a sponsored link. Other profiles appeared beneath these sponsored links in no apparent order.

\subsection{Price of spaces}

The average price of renting a space for a day across the 23 airports was $£ 5.10$. Based on an exchange rate of $£ 1=$ USD\$1.61 (as of 21st July 2011), this figure equates to a price of US\$8.23. The average weekly price was $£ 26.65 / \$ 43.05$ and the average monthly price $f 86.29 / \$ 139.39$. London City airport (LCY) had the most expensive average daily, weekly, and monthly rates of $£ 8.85 / \$ 14.29, £ 43.36 / \$ 70.04$, and $£ 141.67 / \$ 228.25$ respectively of all the airports examined, figures which undoubtedly reflect its geographic location near central London and the Canary Wharf financial district. When LCY is excluded, Liverpool airport in northwest England had the most expensive average daily rate of $£ 6.64 / \$ 10.72$ followed by London/Heathrow with $£ 6.57 / \$ 10.61$ and Edinburgh $£ 6.07 / \$ 9.80$. The most expensive weekly parking rates (LCY excluded) were at Edinburgh at $£ 35.00 / \$ 56.52$, London/Heathrow at $f 32.95 / \$ 53.21$ and London/Stansted at $f 32.27 / \$ 52.11$, while the most expensive monthly rates (LCY excluded) were at London/Heathrow $£ 113.06 / \$ 182.59$, London/Gatwick $£ 100.00 / \$ 161.50$ and Edinburgh $£ 92.50 / \$ 149.38$. In comparison, Birmingham airport in the West Midlands had the cheapest average daily, weekly, and monthly rates at $£ 3.37 / \$ 5.44, £ 20.12 / \$ 32.49$, and $£ 70.00 / \$ 113.06$ respectively.

Unlike official on or off-site airport parking providers, who use sophisticated yield management to extract maximum revenue from their spaces, the prices charged by 
providers advertising on parkatmyhouse.com were fixed and the website emphasised that the price displayed on the website was the price that customers would pay, irrespective of how long in advance they booked. Furthermore, while the official car park operators offer a range of value-added products such as valet parking, in addition to traditional duration based products, the alternative parking providers only offer a single class of service. Moreover, while the official sites are secure, insured, lit, and patrolled by CCTV and security staff 24 hours a day 7 days a week, the alternative residential spaces we identified often had no such security provisions. Consequently, it is unsurprising that the alternative small-scale providers were often able to undercut the official providers. By way of illustration, the average (fixed) price charged by private providers on parkatmyhouse.com for daily, weekly, and monthly rentals around London Stansted airport was $£ 4.70 / \$ 7.59, £ 32.27 / \$ 52.13$, and f88.50/\$142.96 respectively. While the number of different products and use of yield management systems makes direct comparisons very difficult, Table 3 provides an indication of the prices charged by various BAA car parks for a single space booked one day and one month in advance. Prices were obtained from the official BAA car parking website at 2pm on 19 May 2011.

Table 3 Price (f) of parking at official airport car parks at London Stansted.

The cheapest official daily rate in the long stay car park $£ 10.75 / \$ 17.36$ was over six pounds more expensive than the average price charged by parkatmyhouse.com. Similarly, the average weekly rate charged by alternative independent providers $(£ 32.27 / \$ 52.12)$ was less than half the cheapest rate charged by the airport $(£ 70.00 / \$ 113.06)$ in the long stay car park. The difference was even more pronounced for monthly rentals, with the cheapest price offered by the official car parks being $£ 83 / \$ 134.06$ more expensive than the average price offered by the 
alternative providers. While there were only 199 alternative spaces available at Stansted (accounting for less than $1 \%$ of the total number of spaces available at the airport), they had attracted 1,720 bookings. If those customers stayed for a week and would have travelled to the airport by another mode if the cheaper spaces had not been available, the airport would have potentially lost $f 120,400$ pounds $(\$ 194,467)$ in revenue which, in an era of depressed margins and increasing reliance on non-aeronautical revenue streams, is potentially significant.

\subsection{Additional facilities and features}

Leaving aside difficult and perhaps irresolvable questions concerning consumer behaviour and the effect of price on car park decision making and ground access choices to airports, it is interesting to examine the nature and the extent of the various different additional facilities and services that alternative providers offered. For instance, $81 \%$ of all available spaces advised potential customers that they could access their car $24 / 7$. This would, of course, be important for passengers departing or arriving on flights at anti-social hours. Of the $19 \%$ that did not offer unrestricted access, a small number further stipulated that they would not accept bookings from people who needed to access their cars between $11 \mathrm{pm}$ and $7 \mathrm{am}$ in case the noise of the car's engine and doors shutting disturbed either their own family's or their neighbours" sleep and $3 \%$ of providers had a minimum stay requirement (usually a week).

In addition to stipulating terms of access, providers were keen to emphasise that cars using their space(s) would be secure. $44 \%$ of spaces were reportedly permanently lit or covered by motion-sensitive security lighting, $24 \%$ could be gated or secured, and 7\% were under 24-hour CCTV surveillance. Two providers offering spaces near Leeds Bradford airport in the north of England further advised potential customers 
that one of their near-neighbours worked for the local police service and over 30 others right across the country made reference to the fact that property on which the spaces were located was inside a Neighbourhood Watch zone (a local community scheme in the UK in which residents keep an eye on other people's property and look out for suspicious behaviour). As well as access and security, a small number of providers also offered additional „value added" services. $9 \%$ of providers offered to transfer customers and their luggage to/from the local airport in their own vehicles (although customers were expected to pay any appropriate airport drop off charges in addition to their parking fee), $1 \%$ would fully valet vehicles left on their property free of charge, three providers offered overnight accommodation before departure, and one animal-loving family would take care of any small pets while their owner was away and parking on their property.

\subsection{Membership attributes}

While only $47 \%$ of all the provider profiles surveyed on parkatmyhouse.com as part of this research contained information about when they became members of the website, the information these profiles contained provide an indication of the spatial and temporal development of the phenomenon of alternative residential off-site parking provision around UK airports. The rapid growth in the number of independent providers offering alternative airport parking spaces between 22 September 2006 and May 2011 is provided in Figure 3.

Figure 3 Growth in the number of alternative airport parking providers for whom information on joining date was available.

While these figures only refer to providers offering spaces around the UK's 25 busiest passenger airports, they nevertheless demonstrate that the number of 
providers offering such spaces has almost doubled year-on-year. Interestingly, however, these members are not uniformly distributed throughout the UK and the data presented in Figure 4 illustrates that the phenomenon of off-site residential parking provision was initially restricted to, and still largely dominated by, providers in the south east of England (although the number of independent providers offering spaces around airports now includes growing numbers in other regions of the UK).

\section{Figure 4 Temporal development of off-site residential parking providers around} UK airports by region*.

* South East includes London/Heathrow, London/Gatwick, London/Stansted, London/City, London/Luton, Southampton, and Bournemouth airports; Midlands and East Anglia covers Birmingham, East Midlands, and Norwich airports; Northern England includes Liverpool, Manchester, Leeds Bradford, and Doncaster Sheffield airports; Scotland and Northern Ireland includes Edinburgh, Glasgow, Belfast International, Aberdeen, and Glasgow/Prestwick airports, and Southwest England and Wales includes Bristol, Exeter, and Cardiff.

Thus, far from being a phenomenon restricted to the southeast of England, alternative off-site residential parking is now available (albeit perhaps only on a limited basis) at airports throughout the UK and the number of providers offering spaces is increasing year-on-year.

\section{Discussion}

This paper has examined the relatively new phenomenon of off-site residential parking provision around UK airports. Through the systematic in-depth interrogation of three UK-based parking marketplace websites, the paper has offered new empirical insights into the scale and scope of these „alternative" small scale off-site 
parking facilities around the UK"s 25 biggest passenger airports. We contend that the growth of these alternative spaces represents both a challenge and an opportunity to airport operators, local authorities, and airport users. Airports may, and are, losing custom to these alternative providers and suffer a reduction in parking revenue as a consequence. However, increased use of alternative parking spaces may actually impact favourably on individual airport's ground access mode share and as such may actually aid in meeting their sustainable ground access targets if people park off site on private driveways and then catch a train or a bus for the last few miles to the airport. Equally, and without wishing to overstate our case, it is possible that if users of alternative sites arrange to be taken to the airport, the airport may gain additional revenue through the increased use of drop-off zones, for which a fee (typically $\mathrm{f1/ \$ 1.61}$ per drop-off not lasting more than 10 minutes) is levied, although clearly this must be offset against a loss of parking revenue. Changing the modal spilt may also present challenges for airports, particularly if, as is possible and has been suggested by the providers of alternative spaces, users park on driveways near the airport and then walk to the airport terminal. Very few airports are designed for pedestrian access and the health and safety implications of having passengers with heavy luggage walking on major access roads, which often do not have pedestrian walkways, to and from terminal buildings are profound.

The rise of alternative and unregulated off-site residential parking around airports also potentially poses a number of challenges for the local authorities surrounding the airports concerned. The use of these alternative spaces may increase traffic congestion on local roads, pavements may become obstructed by parked vehicles, and new parking restrictions and parking enforcement may have to be introduced to prevent parked vehicles from blocking the highway. 
Similarly, the provision of alternative spaces, though only representing a small percentage of the number available in official airport car parks, introduces a new element of competition and choice for car drivers. This may, in turn, actually increase passenger numbers at airports as the price saved by not using official parking may almost cover the cost of a low cost flight. However, on the downside, users of these alternative spaces have to trade-off the benefits of lower costs with the possible problems associated with facilities that are not as advertised, concerns about possible damage to their vehicles and the insurance implications of leaving their vehicle on private unregulated land (especially where the providers of spaces request car owners leave the keys to their vehicle behind so that alarms can be silenced if they are activated in error). Similarly, private providers of car parking spaces are not bound by the same requirements that official regulated providers are to provide a certain number of spaces for disabled drivers, for example.

There are clearly many aspects to this phenomenon that need to be explored, not least both providers" and customers" motivations for, and experience of, using these alternative sites, as well as more detailed mapping of the locations of these facilities and the impact they have on local congestion, airport revenues, and mode choice. However, while our paper has focused on the provision of alternative parking around airports, we recognise that the phenomenon that we have described is not only restricted to airports. Indeed, our experience of accessing the three virtual parking marketplaces indicate that spaces can be found around most major UK towns and city centres as well as railway stations, sports stadia, hospitals, and sites that generate traffic but which charge for parking on a hourly, daily, or an intermittent basis. Moreover, while we have limited our research to one country, alternative residential parking is not simply a UK phenomenon. Indeed, extensive web searches revealed evidence of a similar number of parking marketplace websites operating in 
the US, Canada, and South Africa.

\section{Conclusion}

Online virtual parking marketplaces have emerged within the last five years to tackle the dual problem of the perceived expense and lack of available car parking spaces around major generators of private vehicular traffic. It is likely that the primary driver is economic. As the cost of living increases, people are looking for ways to generate alternative sources of revenue to supplement their income. Similarly, as motoring costs and the price of airline tickets rise, customers are increasingly looking for value for money and the most cost effective places to park. Increasingly, they may look beyond the traditional airport-operated or off-site regulated commercial car parks towards alternatives that they perceive not only provides better value for money but also offers what is believed to be a better customer service. Our data indicates that these alternative residential parking spaces are rapidly growing in popularity and that increasing numbers of people are choosing to "rent their drives" in order to generate additional money. Clearly, this has a number of potentially serious implications and thus airport operators and local authorities need to be cognisant of the existence of, and the challenges and opportunities associated with, the growth of alternative offsite, mainly residential, parking provision so that they can better plan for, and respond to, its complex revenue, planning, environmental, and consumer implications. Similarly consumers must make a value judgment on the priority they attach to cost, vehicle security, and personal safety in choosing how and when to book car parking spaces and which providers to patronise.

\section{References}

Aldridge, K., M. Carreno, S. Ison, T. Rye, and I. Straker. Car Parking Management at airports: A special case? Transport Policy, 13(6), 2006, 511-521. 
Ashford, N., M. Stanton, and C. Moore, C. Airport Operations: 2nd Ed, McGraw-Hill, London-New York, 1997.

BAA Glasgow. A Surface Access Strategy for Glasgow Airport 2009-2013, 2009.

BAA London Stansted, Leading the way forward: A Surface Access Strategy for Stansted 2008-2015, 2008.

Birmingham International Airport. Moving Together: Airport Surface Access Strategy 2006-2012, 2006.

Civil Aviation Authority (CAA) UK Airport Statistics: 2010-annual, http://www.caa.co.uk/docs/80/airport_data/2010Annual/Table_01_Size_of_UK_Airpor ts_2010_Comp_2009.pdf. Accessed May. 10, 2011.

de Neufville, R, and A. Odoni. Airport Systems: Planning, Design and Management, McGraw Hill, 2003.

Department for Transport. Mode of transport to airport: Selected United Kingdom Airports, 2000-2010. http://assets.dft.gov.uk/statistics/worksheets/avi0107.xls. Accessed July. 22, 2011.

East Midlands Airport. Surface Access Strategy, 2006.

Humphreys, I., and S. Ison. Changing airport employee travel behaviour: the role of airport surface access strategies, Transport Policy, 12(1), 2005, 1-9.

Ison, S., G. Francis, I. Humphreys, and T. Rye. Airport car parking management: issues and policies, In: TRB (Transportation Research Board) 87th Annual Meeting. Washington DC, USA, 13-17 January 2008. 